\title{
Selected papers from the 1st Brazilian Congress on Process Systems Engineering
}

\author{
Maurício B. de Souza Jr. ${ }^{1}$ Argimiro R. Secchi ${ }^{2}$
}

Published online: 16 September 2021

C Associação Brasileira de Engenharia Química 2021

For the past half-century, the Brazilian Process Systems Engineering community (PSE-BR) has experienced a history of excellence. In both the academy and industry, developments such as process modeling, simulation, optimization, synthesis, and control, among others, have found great acceptance. However, until recently, there was not a specific meeting for these professionals.

The I Brazilian Congress on Process Systems Engineering (PSE-BR 2019) was held at Universidade Federal do Rio de Janeiro (UFRJ) by the Process Systems Engineering (PSE) Thematic Section of the Brazilian Association of Chemical Engineering (ABEQ) from 20th to 22nd May 2019. The event was organized jointly by UFRJ and Universidade do Estado do Rio de Janeiro (UERJ), Pontifícia Universidade Católica (PUC-RJ), Universidade Federal Fluminense (UFF) and Universidade Federal Rural (UFRRJ).

With 265 participants, the PSE-BR 2019 included 36 oral presentations and 165 posters in the following thematic areas: (1) Process Modelling and Simulation; (2) Process Optimization; (3) Process Synthesis and Design; (4) Process Integration and Intensification; (5) Process Control and Instrumentation; (6) Data Mining and Machine Learning; (7) Production Planning and Scheduling; (8) Molecular Modelling and Product Design; (9) Fault Detection and Diagnosis; and (10) Industrial Application of PSE Toolbox.

There were also two guest lectures given by international authorities in the field of Artificial Intelligence: "When

Maurício B. de Souza Jr.

mbsj@eq.ufrj.br

Argimiro R. Secchi

arge@peq.coppe.ufrj.br

1 Departamento de Engenharia Química/Escola de Química, Universidade Federal do Rio de Janeiro, Cidade Universitária, Rio de Janeiro, RJ 21941-909, Brazil

2 Programa de Engenharia Química, COPPE, Universidade Federal do Rio de Janeiro, Rio de Janeiro, RJ 21941-972, Brazil
Machine Learning Meets Robust Optimization and Control: Data-driven Adaptive Robust Optimization Models, Algorithms and Applications for Industry 4.0", by Professor Fengqi Yu (from Cornell University), and "Artificial Intelligence in Process Systems Engineering: Quo Vadis?", by Professor Venkat Vankatasubramanian (from Columbia University). Nine other lectures were given by Brazilian experts, with themes ranging from techno-economic and environmental analysis of new industrial processes to "digital twins" in the chemical industry. All details of the PSE-BR 2019 and the PSE-BR channel can be found at http://www.abeq. org.br/psebr.

In this Special Section, the Brazilian Journal of Chemical Engineering is publishing a total of 9 selected papers of works presented at PSE-BR 2019. The published papers reflect the diversity of thems of the congress. Their selection was very tough. The PSE-BR Scientific Committee-chaired by Professor Maurício B. de Souza Jr. (UFRJ)—evaluated 73 expanded abstracts submitted to the PSE-BR. The committee made a preliminary selection of 25 of these abstracts for subsequent submission, in full paper form, to the BJCE, where they were submitted to an independent review by the journal's Editorial team.

At the end of PSE-BR 2019, its president, Professor Argimiro R. Secchi stated: "I think we've already left a good reference for upcoming events". This collection of papers reinforces this expectation.

Maurício B. de Souza Jr. and Argimiro R. Secchi

Publisher's Note Springer Nature remains neutral with regard to jurisdictional claims in published maps and institutional affiliations. 